\title{
A MODEL FOR CAVITATION-INDUCED PRIMARY BREAK-UP OF VISCOUS LIQUID SPRAYS
}

\author{
RATHESAN RAVENDRAN ${ }^{1,2}$, BENNY ENDELT $^{1}$, \\ JESPER DE CLAVILLE CHRISTIANSEN ${ }^{1} \&$ PETER JENSEN $^{1,2}$ \\ ${ }^{1}$ Department of Materials and Production, Aalborg University, Denmark \\ ${ }^{2}$ Hans Jensen Lubricators A/S, Denmark
}

\begin{abstract}
In this paper, a new model for cavitation induced primary break-up is proposed, which is able to map the influence of cavitating nozzle flow on spray formation. The model is applicable for viscous liquid sprays, where the Reynolds number is below 800 . For such viscous spray systems, liquid break-up is enhanced when cavitation bubbles burst at the nozzle exit. The proposed model describes the transition from the flow inside the nozzle, modelled using a homogeneous equilibrium model (HEM) method, to the first primary droplets modelled using a Eulerian-Lagrangian method. Thus, providing the boundary conditions for the calculation of the secondary break-up and spray formation. The nozzle exit is divided into a definite number of patches, and liquid momentum and density from each patch are used to initialize the primary droplets. Using this method, the influence of bursting cavitation bubbles and asymmetrical properties of viscous sprays can be identified. The model has been implemented in the open-source CFD software package OpenFOAM and a first validation has been done using high-speed shadowgraphic imaging.
\end{abstract}

Keywords: spray formation, cavitation, primary break-up, numerical simulation, viscous liquids, OpenFoam.

\section{INTRODUCTION}

It is generally accepted that cavitation inside spray nozzles have a great importance on the break-up of liquid jets [1]-[5]. Cavitation is the formation of vapor cavities inside the liquid due to evaporation, which takes places, when the local pressure of the liquid drops below the vapor pressure. The subsequent collapse of these cavities introduces disturbances to the liquid stream that lead to a faster breakup of the exiting jet [6]-[8].

Even in high pressure spray systems, the liquid jet does not atomize greatly when disturbances caused by cavitation are not present [9]. This is especially true for viscous liquids, which are difficult to atomize using pressure spray systems unless high fluid pressure is applied [10], [11].

The internal nozzle cavitation has been studied intensively, and research has shown that cavitation is promoted by a variety of factors as e.g. sharp inlet orifices, needle lift, curvature of the inlet edge, liquid properties, and system pressure [12]-[15].

Ravendran et al. [15], investigated the atomization of viscous liquids, and showed that the non-axial injection conditions lead to a swirling liquid flow inside the nozzle. Thus, leading to the development of cavitation strings in the core of the liquid vortices. Fig. 1 shows, shadowgraphic images of the two cavitation strings inside the studied transparent spray nozzle.

It was shown that the cavitation strings increase the degree of atomization greatly, this is only the case when the cavitation strings extends to the exit of the nozzle. However, when the cavitation collapses in the nozzle volume, the viscous liquid is able to stabilize the stochastic disturbances introduced by the cavitation. Fig. 2(a) shows an image of the exiting spray, when the cavitation collapses in the nozzle volume, whereas Fig. 2(b) shows a case where the liquid break-up is enhanced due to bursting cavitation bubbles at the nozzle exit. 


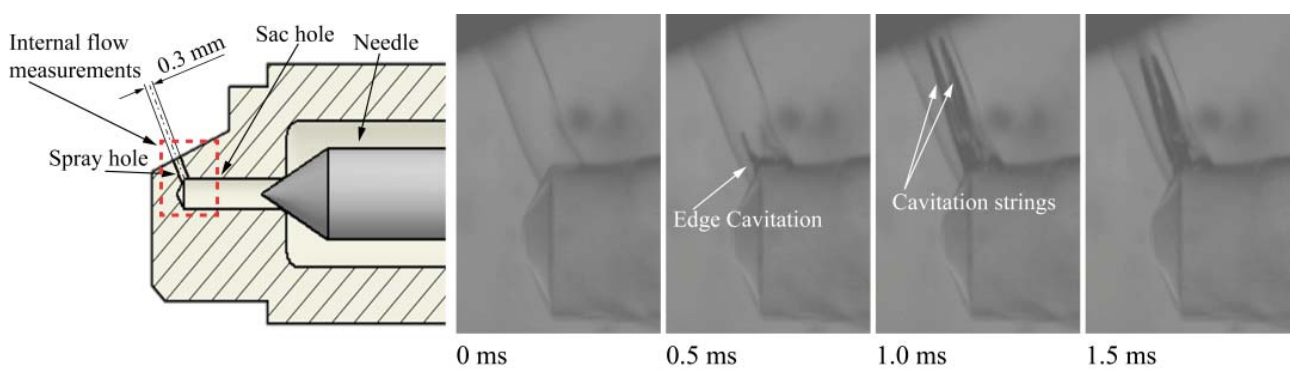

Figure 1: Shadowgraphic images of the developing cavitation strings inside the studied transparent spray nozzle.

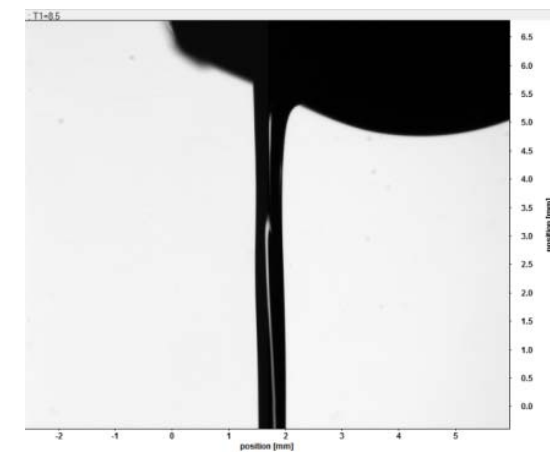

(a)

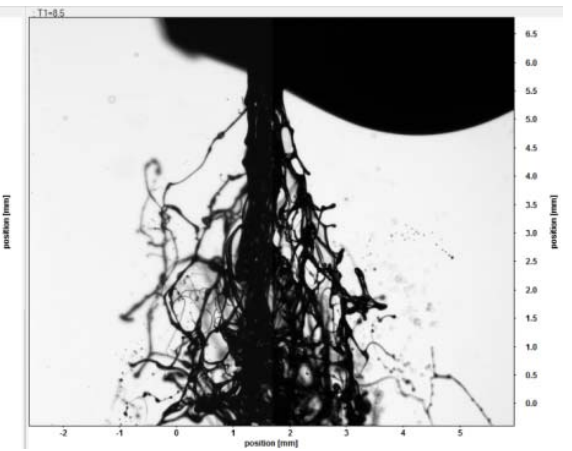

(b)

Figure 2: Near-nozzle images of the spray formation. Images are taken with a shadow imaging system from LaVision. (a) Cavitation collapses in the nozzle volume; (b) Cavitation bursts outside the nozzle exit.

Several methods exist and are implemented in commercial CFD-codes for simulating the spray formation using the Lagrangian method as e.g. Taylor Analogy, et al., Break-up [16]. However, these models need sub-models to describe the transition from the nozzle flow to the primary droplet, as illustrated in Fig. 3. This coupling has been the focus of several authors, as accurate numerical simulation of spray formation is of great interest [6], [17], [18]. Especially, there is a high interest of modeling low viscous liquids such as water and diesel fuel, and not much work has been performed on cavitation induced primary break-up of viscous liquids. This leads to the objective of this study.

In this paper, a method for coupling the internal flow and the subsequent spray is proposed. The purpose of the new primary breakup model is to describe the transition from the flow inside the nozzle to the first primary droplets, and thereby providing all starting conditions for the calculation of secondary break-up and spray formation. The input data for the new model are based on the detailed numerical investigations of the nozzle flow performed in [15]. The first validation of the model has been done using high-speed shadowgraphic imaging, however this has not been the scope of this paper. 


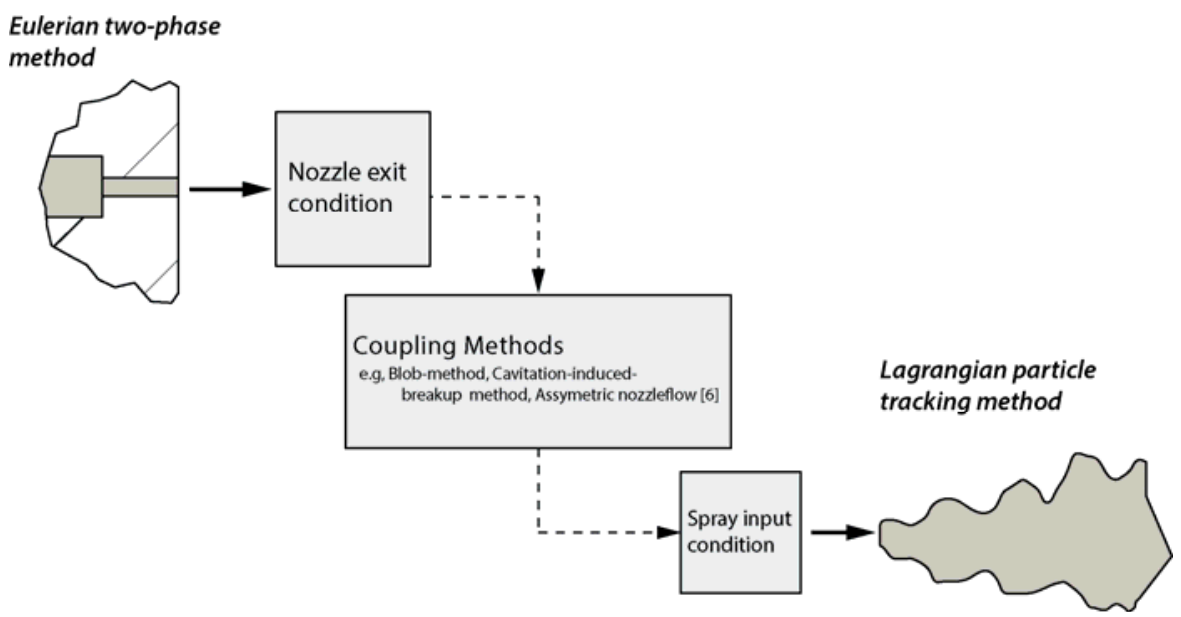

Figure 3: Illustration of the numerical simulation approach used in this paper.

\section{NUMERICAL APPROACH}

The simulation approach is divided in two steps, as illustrated in Fig. 4. Firstly, simulation of the liquid flow and cavitation inside the nozzle is done using the two-phase fluid mixture Schneer and Saur model [15], [19], [20]. Secondly, simulation of the spray formation is done using a standard Lagrangian KHRT secondary break-up model. The two simulation steps are connected using a coupling model, which translates the flow inside the nozzle to the first primary droplets at the nozzle exit and provide the starting conditions for the spray formation.

The focus of the following section is therefore to describe the proposed coupling model, as the simulation of the internal flow is described in detail in [15], and the standard KHRT-model is for example documented in [6], [18], [21].

\subsection{Primary break-up model}

The purpose of the coupling model is to initiate the primary droplets using the nozzle exit conditions. The nozzle exit is therefore separated into a defined number of boundary patches, from which liquid velocity $(U)$ and degree of cavitation $(\alpha)$ are used to calculate the diameter of the primary droplet $\left(D_{i}\right)$, mass flow rate $\left(\dot{m}_{l}\right)$, and spray angle $\left(\varphi_{i}\right)$ at each patch $(i)$.

The location of each patch is randomly selected, in order to suppress geometrical effects when introducing a defined boundary grid. This approach makes the model flexible and applicable for different nozzle geometries. However, as patches are allowed to overlap and exceed the diameter of the nozzle, minor errors in spray angle are expected. The first droplets at the nozzle exit is introduced using the so-called blob-method, where the assumption is that the dense spray near the nozzle can be represented by spherical droplets with uniform size. The diameter of these droplets equals the nozzle hole diameter. The number of the droplets injected per unit time is determined from the mass flow rate. The mass flow rate of the primary droplets is calculated using eqn (1).

$$
m_{i}(t)=\rho_{l} \cdot A_{\text {patch }} \cdot U_{i}(t),
$$

where $\rho_{l}$ is the liquid density, $A_{\text {patch }}$ is the area of the selected patch, $U_{i}(t)$ is the velocity of the liquid composed of the three components in $\mathrm{x}, \mathrm{y}$, and z-direction. 


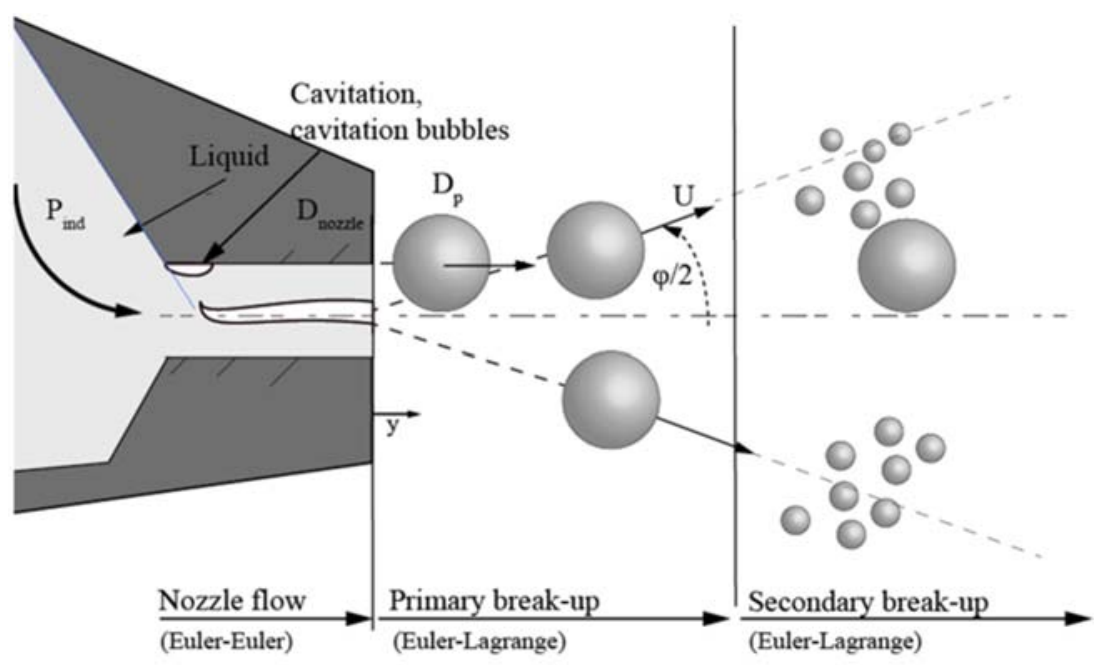

Figure 4: Illustration of the purpose of the different coupling methods.

The direction of the droplets leaving the nozzle exit is defined using the spray angle. These parameters are highly influenced by the degree of cavitation at the nozzle exit, as busting of cavitation bubbles leads to increased spray angle $\left(\varphi_{i}\right)$. The degree of cavitation is expressed in terms of vapor volume fraction $\left(\alpha_{i}\right)$, which is directly extracted from the internal flow simulations. The vapor volume fraction is described by a number from 0 to 1 , for $\alpha_{i}<1$ the patch cavitates. The spray angle $\left(\varphi_{i}\right)$ is determined using eqn (2).

$$
\varphi_{i}=\left\{\begin{array}{ll}
0 & \alpha_{i}=1 \\
\cos ^{-1}\left(\frac{U_{i, p l a n e} \cdot U_{i, y}}{\left\|U_{i, \text { plane }}\right\| \cdot\left\|U_{i, y}\right\|}\right) & \alpha_{i}<1
\end{array},\right.
$$

where $U_{i, y}$ is the velocity vector of the liquid perpendicular to the nozzle exit, and is defined by $U_{i, p l a n e}=U_{i, x}^{2}+U_{i, z}^{2}$ and describes the velocity components parallel to the nozzle exit.

\subsection{Boundary conditions}

The internal flow and droplet breakup simulations are performed using the open source finite-volume CFD software OpenFoam 3.0. The proposed coupling model is a subroutine written in Matlab.

The boundary conditions for the simulations are based on experimental data, which are thoroughly described in [15]. However, the experimental conditions are summarised in Table 1.

\section{RESULTS AND DISCUSSION}

The results of the nozzle flow simulations are shown in Fig. 5. The velocity at the nozzle exit is shown in Fig. 5(a), where the fringe level indicates the velocity in y-direction $\left(U_{y}\right)$ and the vector field represents velocity components in the $x z-$ plane $\left(U_{x}\right.$ and $\left.U_{z}\right)$. It is seen that the 
swirling flow is prominent at higher temperatures, whereas at low temperatures the flow is non-swirling and axisymmetric.

Fig. 6 shows the computational and experimental results of the spray formation for injection case 1 . The numerical simulations are performed using $\mathrm{N}_{P}=100$. The simulation results show a dense liquid core in the center of the spray, and smaller dispersed ligaments away from the center. These observations agree with the experimental observations. It is also important to highlight that the proposed model is capable of predicting the spray structure and asymmetrical shape apart from the spray tip penetration.

Table 1: Experimental test conditions.

\begin{tabular}{|l|l|r|}
\hline 1. Pressure system & Pressure pump & HJ - Lubtronic \\
\hline & Pressure supply & $70 \mathrm{bar}$ \\
\hline & Piston diameter & $6 \mathrm{~mm}$ \\
\hline & Oil temperature & $60,80,100^{\circ} \mathrm{C}$ \\
\hline & Oil type & Mobilgaard 570 \\
\hline & & HJ - SIP \\
\hline & Injector type & $40 \mathrm{bar}$ \\
\hline & Opening pressure & $1 \mathrm{bar}$ \\
\hline & Ambient pressure & 25 \\
\hline & Ambient temperature & \\
\hline & & Photron Fastcam SA5 \\
\hline & Camera type & $1000 \mathrm{~W}$ LED-lamp \\
\hline & Illumination & $1 / 15000 \mathrm{fps}$ \\
\hline & Frame rate & \\
\hline & Shutter speed & \\
\hline & & \\
& &
\end{tabular}
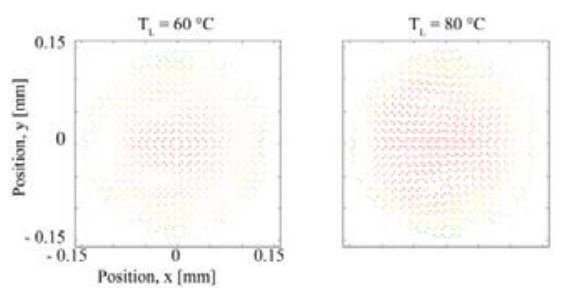

(a)

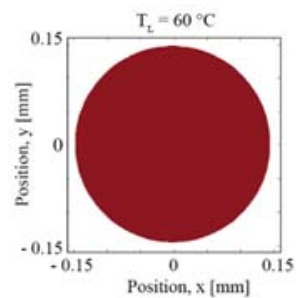

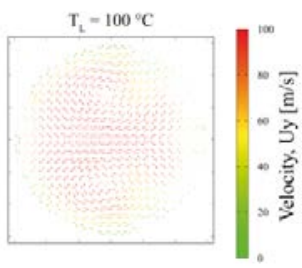

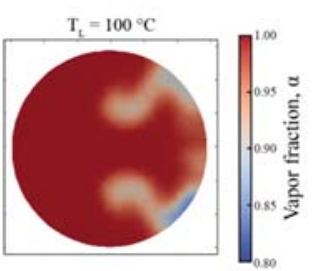

(b)

Figure 5: The results of the internal nozzle simulations. (a) Velocity vector field at nozzle exit; (b) The results of the internal nozzle simulations. 


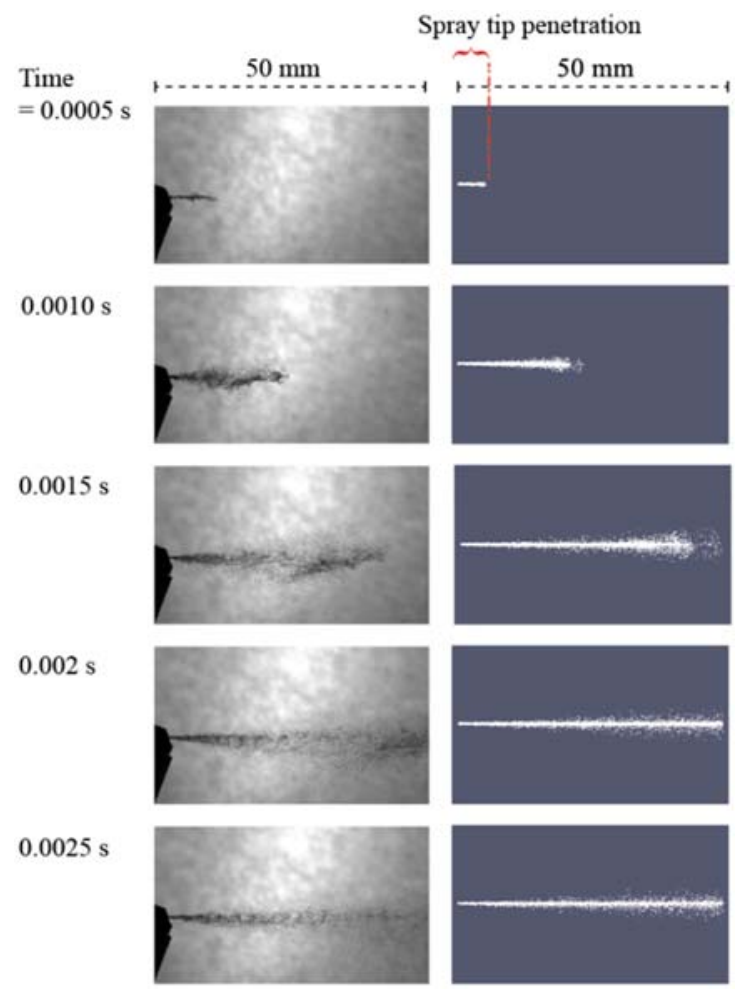

Figure 6: Spray formation due to cavitation induced breakup (Comparison between experiment and numerical simulation). The temperature of the injected liquid is $\mathrm{T}_{\mathrm{L}}=100^{\circ} \mathrm{C}$. The numerical simulations are performed using 100 patches.
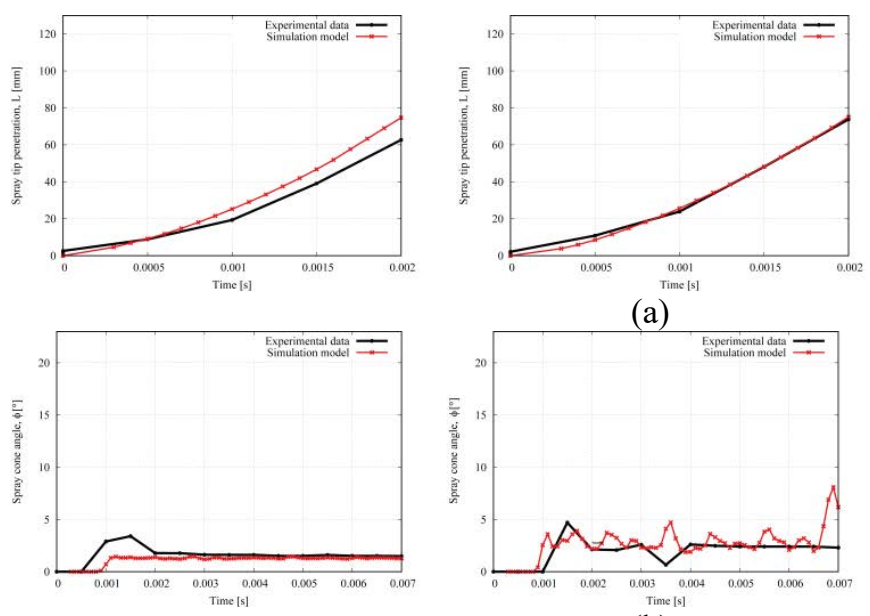

(a)

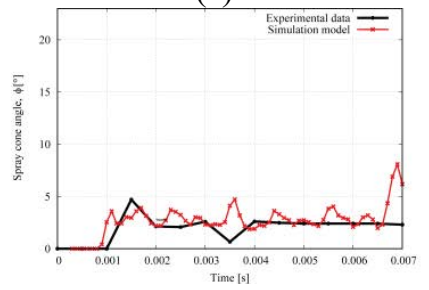

(b)
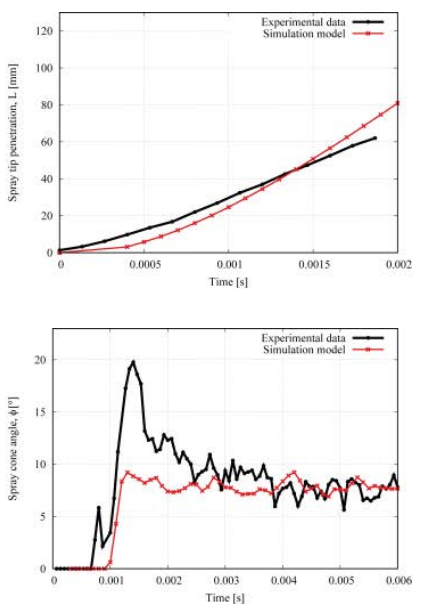

Figure 7: The results of the internal nozzle simulations. (a) Velocity vector field at nozzle exit; (b) The results of the internal nozzle simulations. 
The spray tip penetration $\mathrm{L}$ and cone angle $\varphi$ is shown in Fig. 7. There is a good agreement between the calculated and measured spray tip penetration, which is due to the good prediction of the liquid flow from the internal nozzle flow simulations.

Fig. 7(b) shows, that the computed spray angle for different nozzle flow cases can be predicted adequately. When the liquid temperature is $60^{\circ} \mathrm{C}$, there is no cavitation at nozzle exit, thus the exiting liquid is a jet. As the degree of cavitation increases in $\mathrm{T}_{\mathrm{L}}=80^{\circ} \mathrm{C}$ and $\mathrm{T}_{\mathrm{L}}=100^{\circ} \mathrm{C}$, the spray angle increases as well. There is a very good agreement between the calculated and measured spray cone angle.

\section{CONCLUSION}

In this study, a new method for simulating cavitation induced breakup for viscous liquids is proposed. The proposed model describes the transition from the flow inside the nozzle, modelled using a homogeneous equilibrium model (HEM) method, to the first primary droplets modelled using a Eulerian-Lagrangian method. Thus, providing all starting conditions for the calculation of the secondary break-up and spray formation.

The model is able to predict the spray angle and spray tip penetration sufficiently for different nozzle flow cases, where the degree of cavitation differs.

Further investigations have to be performed in order to determine whether the droplet size can be predicted using the proposed method. Furthermore, the importance of the model constants used for the simulation is not discussed in this study.

\section{REFERENCES}

[1] Fansler, T.D. \& Parrish, S.E., Spray measurement technology: a review. Meas. Sci. Technol., 26(1), p. 12002, 2015.

[2] Le Moyne, L., Trends in atomization theory. Int. J. Spray Combust. Dyn., 2, pp. 49-84, 2010.

[3] Dong, P., Inaba, T., Nishida, K. \& Shimo, D., Characteristics of the internal flow and the near-field spray of a single-hole injector and a multi-hole injector for diesel engines. Proc. Inst. Mech. Eng. Part D J. Automob. Eng., 230(5), pp. 632-649, 2016.

[4] Jollet, S., Heilig, A., Bitner, K., Niemeyer, D. \& Dinkelacker, F., Comparison of experiments and numerical simulations of high pressure transparent injection nozzles Experimental test-rig, pp. 1-4, 2013.

[5] Sou, A., Hosokawa, S. \& Tomiyama, A., Effects of cavitation in a nozzle on liquid jet atomization. Int. J. Heat Mass Transf., 50(17-18), pp. 3575-3582, 2007.

[6] Baumgarten, C., Mixture Formation in Internal Combustion Engine. Springer:Verlag Berlin Heidelberg, 2006.

[7] Bergwerk, W., Flow pattern in diesel nozzle spray holes. Arch. Proc. Inst. Mech. Eng., 173(1959), pp. 655-660, 1959.

[8] Dumouchel, C., Leboucher, N. \& Lisiecki, D., Cavitation and primary atomization in real injectors at low injection pressure condition. Exp. Fluids, 54(6), 2013.

[9] Dabiri, S., Sirignano, W.A. \& Joseph D.D., Cavitation in an orifice flow. Phys. Fluids, 19(7), p. 72112, 2007.

[10] Tamaki, N. \& Shimizu, M., Enhancement of atomization of high-viscous liquid jet by pressure atomized nozzle. ILASS Eur. 12th Trienn. Int. Conf. Liq. At. Spray Syst., 2002.

[11] Khmelev, V.N., Shalunov, A.V. \& Smerdina, E.S., The cavitation spraying of the viscous liquids. Int. Work. Tutorials Electron Devices Mater. EDM - Proc., pp. 269-273, 2006. 
[12] Jolletm, S., Hansenm, H., Bitner, K., Niemeyer, D. \& Dinkelacker, F., Transparent nozzles with high pressure conditions. ILASS Eur. 26th Annu. Conf. Liq. At. Spray Syst., pp. 8-10, 2014.

[13] Pratama, R.H., Sou, A., Wada, Y. \& Yokohata, H., Cavitation in mini-sac nozzle and injected liquid jet. ICLASS 2015, 13th Int. Conf. Liq. At. Spray Syst., 1, pp. 3-9, 2015.

[14] Andriotis, A., Gavaises, M. \& Arcoumanis, C., Vortex flow and cavitation in diesel injector nozzles. J. Fluid Mech., 610, pp. 195-215, 2008.

[15] Ravendran, R., deClaville Christiansen, J., Jensen, P. \& Endelt, B., Numerical study of cavitation of high-viscous liquid spray systems. ILASS Am. 28th Annu. Conf., pp. 1-12, 2016.

[16] Baumgarten, C., Stegemann, J. \& Merker, G., A new model for cavitation induced primary break-up of diesel sprays. Zaragoza, 9(11), 2002.

[17] Soriano-Palao, O.J., Sommerfeld, M. \& Burkhardt, A., Modelling the influence of the nozzle geometry on the primary breakup of diesel jets. Int. J. Spray Combust. Dyn., 6(2), pp. 113-146, 2014.

[18] Mohan, B., Yang, W. \& Chou, S.K., Development of an accurate cavitation coupled spray model for diesel engine simulation. Energy Convers. Manag., 77, pp. 269-277, 2014.

[19] Yuan, W., Sauer, J. \& Schnerr, G.H., Modeling and computation of unsteady cavitation flows in injection nozzles. Mec. Ind., 2(5), pp. 383-394, 2001.

[20] Mohan, B., Yang, W. \& Chou, S., Cavitation in Injector Nozzle Holes - A Parametric Study. Eng. Appl. Comput. Fluid Mech., 8(1), pp. 70-81, 2014.

[21] Reitz, R.D. \& Beale, J.C., Modeling Spray Atomization With the KelvinHelmholtz/Rayleigh-Taylor Hybrid Model. At. Sprays, 9(6), pp. 623-650, 1999. 